\title{
Urbanizar las pasiones: la simpatía humeana y el afinamiento moral
}

\section{Passions Becomes Civilized: Hume's Sympathy and the Moral Refinement}

\author{
Julio Seoane Pinilla ${ }^{1}$ \\ Universidad de Alcalá (España)
}

Recibido: 03-05-18

Aprobado: 21-06-18

\section{Resumen}

En este trabajo pretendo mostrar el modo como la simpatía humeana sirve para (a) convertir las pasiones barrocas en sentimientos morales con los que (b) el interés puede establecerse como algo admisible en un comportamiento virtuoso. Ello supone la admisión de que no hay moralidad sino en un contexto social desde el cual se afinan los sentimientos de un modo reflexivo, aunque no únicamente racional siguiendo el mismo modelo que se usa para afinar el sentido del gusto.

Palabras-clave: Hume, Simpatía, Gusto, Sociabilidad Moderna.

\begin{abstract}
In this work I try to show the way in which Hume's sympathy (a) changes the baroque passions into moral sentiments. In this way (b) interest can be established as something admissible in a virtuous behavior. This supposes the admission that there is no morality out of a social context where such sentiments are refined in a reflective way -although not only rational- following the same model used to refine the sense of taste.
\end{abstract}

Key-words: Hume, Sympathy, Taste, Modern Sociability.

\footnotetext{
${ }^{1}$ (julio.seoane@uah.es). Julio Seoane Pinilla es profesor en la Universidad de Alcalá. Estudioso del siglo XVIII ha publicado diferentes textos dedicados a descubrir la cara menos conocida de la Ilustración y en esta misma línea ha traducido e introducido diferentes obras de autores ilustrados. Todos estos estudios históricos los ha hecho siempre con vistas a intervenir en las discusiones contemporáneas de filosofía moral y de educación de la ciudadanía, materias sobre las cuales también ha publicado algunos libros, así como distintos artículos en revistas especializadas.
} 


\section{De las pasiones a los intereses}

Hace ya tiempo que Allbert Hirschman sugirió que la moderna sociedad capitalista no hubiera podido aparecer sin un pequeño pero importante cambio semántico. A saber, el que sustituyó los términos "pasión" y "vicio" por otros menos cargados de contenido moral como los de "ventaja" e "interés". Aunque en su clásico Las pasiones y los intereses apenas le nombra, es Mandeville quien ejemplifica del mejor modo la necesidad de esta variación semántica que a la postre se mostró revolucionaria. La crudeza con la que en La fábula de las abejas es descrita la nueva sociedad comercial, la sociedad capitalista que aparecía ya con toda su fuerza, avanzaba la necesidad de presentar de mejor manera la apuesta por el progreso y la riqueza comercial. Es fácil ver el motivo de esta necesidad. Hoy no resulta chocante considerar que si queremos un mundo rico y próspero debemos admitir que el interés debe tener alguna parte en nuestras organizaciones sociales; de hecho nuestro mundo realmente se ha construido buscando el modo como los intereses se pueden domeñar a fin de que no choquen con violencia y coadyuven a construir esa riqueza que a todos nos es preciosa. A nadie le extrañaría escuchar a mis alumnas cuando se reafirman en la creencia de que el interés propio en mayor o menor medida debe ser admitido como parte de la esencia humana. Pero si en lugar de interés usamos la palabra que aún manejaba Mandeville, vicio, creo que se admitirá que las cosas resultan un poco diferentes.

Los vicios privados, convenientemente manejados por un hábil político, generan beneficios públicos era un lema que debía ser reformulado. La palabra vicio llevaba una tremenda carga negativa, al igual que la admisión mandevilleana de que en verdad no actuamos sino desde nuestro particular amor a nosotros mismos, desde nuestro egoísmo. Se puede recordar el mundo barroco que Mandeville se atrevió a desvelar simplemente trayendo a la memoria a La Rochefoucauld a quien aquel leía con placer. O releyendo Gargantúa y Pantagruel, la célebre obra de Rabelais donde el vicio, el regocijo en el propio placer, tiene no poco de escatológico, brutal y poco delicado. Si observamos las dos imágenes con las que muy posteriormente (y posiblemente menos brutalmente) G. Doré ilustró la obra de Rabelais, podemos percibir claramente qué se entendía cuando se oyó por vez primera a Mandeville. La fábula es una alabanza de las escenas de Gargantúa pues aunque viciosas y desagradables tienden a hacer circular la riqueza (los proveedores de vituallas, sin ir más lejos, se frotarían las manos con algo tan desagradable como la gula de Gargantúa); pero espero que se vea que una nueva sociedad no podía tomar a Mandeville sin hacerle alguna reforma. Y eso fue el cometido principal de la Ilustración escocesa.

${ }^{2}$ Albert O. Hirschmann, Las pasiones y los intereses: argumentos politicos en favor del capitalismo previos a su triunfo, Barcelona, Península, 1999, p. 42

Araucaria. Revista Iberoamericana de Filosofía, Política, Humanidades y Relaciones Internacionales, año 20, $\mathrm{n}^{\circ} 40$. Segundo semestre de 2018. Pp. 311-332. ISSN 1575-6823 e-ISSN 2340-2199 doi: 10.12795/araucaria.2018.i40.14 

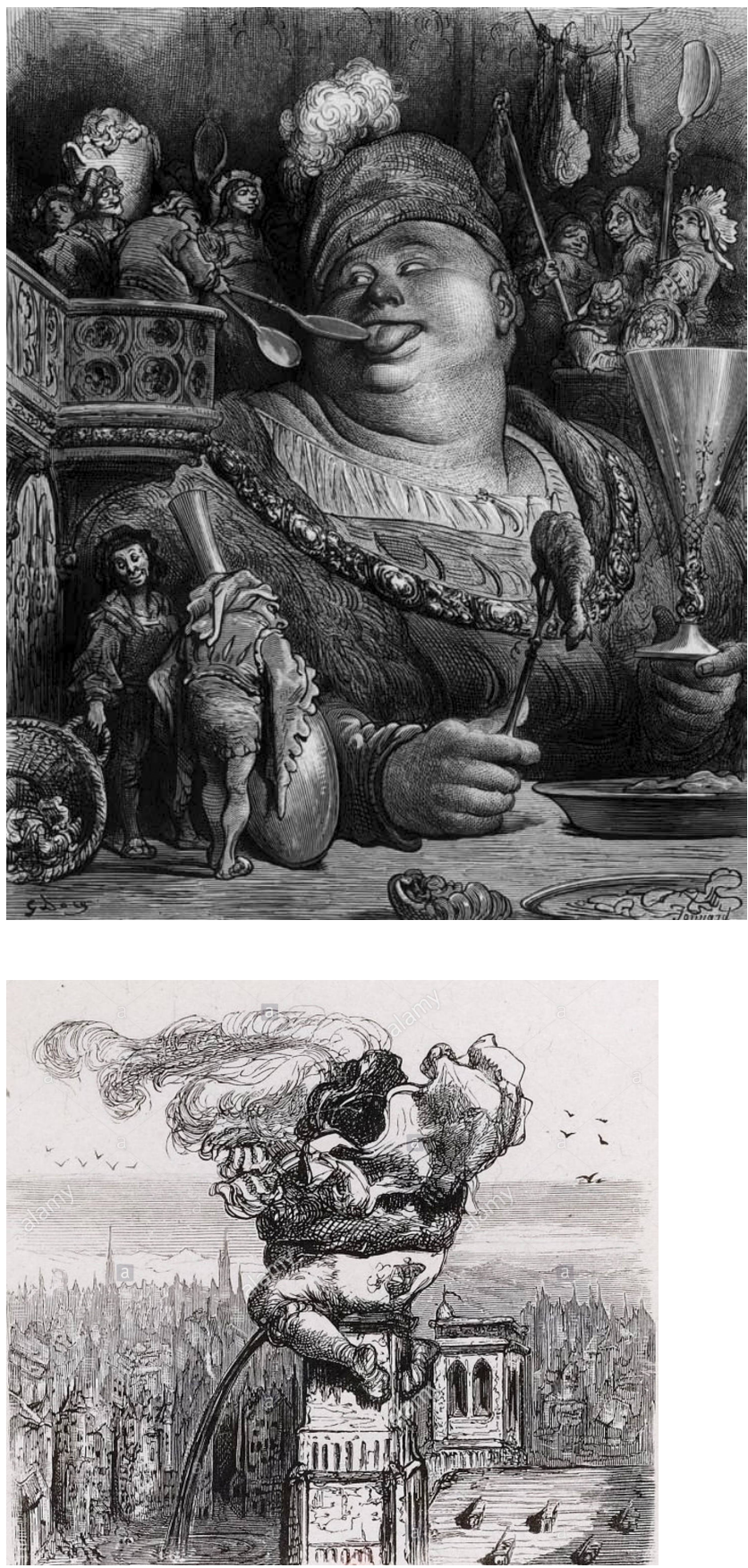

Araucaria. Revista Iberoamericana de Filosofia, Política, Humanidades y Relaciones Internacionales, año 20, $\mathrm{n}^{\circ} 40$ Segundo semestre de 2018. Pp. 311-332. ISSN 1575-6823 e-ISSN 2340-2199 doi: 10.12795/araucaria.2018.i40.14 
No sólo los escoceses se plantaron frente a Gargantúa, también en el mundo francés, tal y como muestra Hirschman, se vio la necesidad de urbanizar el término "egoísmo" que parecía tan común al mundo moderno; pero es en Escocia donde de manera más evidente se hizo este cambio que pasaría a toda la Ilustración. En verdad, Mandeville marcó el campo de juego en el que jugaría toda la Ilustración escocesa, desde su progenitor, Hutcheson, hasta Hume, Smith, Millar, Steuart y también el mismo Ferguson. La primera línea que se escribió "en escocés" vino desde Irlanda con la pluma de Hutcheson en un ataque furibundo contra Mandeville y una partisana defensa del más caballeroso mundo de Shaftesbury, ahora bien, ya en la cuarta línea de tal ataque se vio la necesidad de conceder algo al primero y negárselo al segundo. La concesión era sencilla pero definitiva: de alguna manera debía de admitirse alguna dosis de interés propio, de egoísmo, si queríamos consolidar la rica sociedad de comienzo del XVIII ${ }^{3}$. Cómo hacer tal cosa sin caer en la barroca descripción de Mandeville-La Rochefoucauld-Rabelais fue el trabajo de los ilustrados escoceses que, se debe admitir, culminó con la propuesta de A. Smith según la cual el interés propio (la traducción que consiguieron dar a "egoísmo") no sólo ha de ser admitido en la composición de las modernas sociedades comerciales, sino que es preciso para la riqueza de la nación y para el establecimiento de la libertad.

Lo que se negaba a Shaftesbury era el reconocimiento de que ya no estaban los tiempos para éticas propias de caballeros y debía pensarse para quienes pagaban a todos los pensadores escoceses permitiéndoles dedicarse a sus labores, a saber los merchants. Aunque Hutcheson caminaba demasiado cerca de su admirado Shaftesbury tal y como le echaría en cara Hume, lo cierto es que él mismo se daba cuenta de que la universalidad moral, los preceptos éticos, las propuestas legales y políticas no podían venir de una especie de caballerosa humanidad, sino que tenía todo ello que establecerse de un modo claro y distinto desde un lugar que todos, y no sólo los caballeros, pudieran recoger.

\section{El campo de juego que Mandeville establece}

Era evidente que Mandeville había acertado en varios aspectos que serán a partir de los que Escocia intentará pensar a fin de hacerlos más digeribles. En primer lugar acertó en el hecho de que "no es por la benevolencia del carnicero, del cervecero o del panadero que podemos contar con nuestra cena,

\footnotetext{
${ }^{3}$ Una riqueza que como el mismo Mandeville apuntó, no se establecía sólo en lujos de algunos pudientes, sino también en hospitales, escuelas de caridad, mejores condiciones de trabajo dentro de lo posible, etc.
}

Araucaria. Revista Iberoamericana de Filosofia, Política, Humanidades y Relaciones Internacionales, año 20, $\mathrm{n}^{\circ} 40$. Segundo semestre de 2018. Pp. 311-332. ISSN 1575-6823 e-ISSN 2340-2199 doi: 10.12795/araucaria.2018.i40.14 
sino por la atención a su propio interés"4: la búsqueda de beneficio propio era lo que llevaba fundamentalmente a la nueva sociedad comercial a la que nadie quería renunciar ${ }^{5}$. En segundo lugar acertó al señalar que si la humanidad en la búsqueda egoísta de su propio beneficio no se destruye a sí misma es porque una organización política, social y moral ha conseguido anular las pasiones más dañinas convenciendo a los individuos, mediante el orgullo primero y el apego a sí después, de que se puede obtener más placer, amén de incrementar la riqueza social, renunciando a la inmediata satisfacción de los deseos primeros que se pudieran tener. Esto último fue la tarea que La fábula asignó al hábil político.

El "hábil político" es en verdad una metáfora que trata de expresar las fuerzas sociales que son capaces de contraponer pasiones contra pasiones a fin de reconducir las que serían menos provechosas para la riqueza de la nación. En este punto Hirschman ya señaló que dentro del mundo que trataba con las pasiones locas e irracionales, un mundo que según él se desarrolló hasta casi los albores del XVIII, era común la idea de oponer pasiones a pasiones como el único modo de dominar la locura irracional de éstas. Es su idea que el principio de pasión compensativa había surgido en el siglo XVII a partir de la imagen sombría que entonces se tenía de la naturaleza humana y de la creencia general de que las pasiones son peligrosas y destructivas ${ }^{6}$. En este sentido la forma más elaborada de presentar tal tesis (y posiblemente también la última) fue la de La Rochefoucauld quien no dudaba en afirmar de mil maneras que el vicio entra en la composición de las virtudes como el veneno en la de las medicinas ${ }^{7}$. Pues bien en el curso del XVIII tanto la naturaleza humana como las pasiones fueron ampliamente rehabilitadas y lo fueron porque poco a poco adquirieron la forma de "medicinas" indispensables para el progreso social. Este fue el camino que tomó La fábula y con ella, posiblemente sin saberlo, Mandeville solicitó un esfuerzo para liquidar el Barroco y comenzar a ser "modernos y comerciales". $\mathrm{Y}$ lo hizo en dos pasos que pusieron en bandeja tal cambio.

El primero de tales pasos, que es el que domina la primera parte de La fábula es aquel que supone que la combinación de "venenos" es posible merced al orgullo, poderosa pasión capaz de luchar contra cualquier otra y vencerla. La apuesta por el orgullo está aún en la línea de La Rochefoucauld

${ }^{4}$ A. Smith, An Inquiry into the Nature and Causes of the Wealth of Nations, Londres, Methuen, 1904 (reeditado por Liberty Fund) libro I, cap. 2, p. 16.

5 "Querer gozar de los beneficios del mundo, y ser famosos en la guerra, y vivir con holgura, sin grandes vicios, es vana utopía en el cerebro asentada [...] la virtud sola no puede hacer que vivan las Naciones esplendorosamente; las que revivir quisieran la Edad de Oro, ha de liberarse de la honradez como de las bellotas" (B. Mandeville, The Fable of Bees, Oxford, 1924, p. 36-37 [La fábula de las abejas, México, FCE, 1982, p.21]).

${ }^{6}$ Albert O. Hirschman, Op. Cit., p. 50

7 "Los vicios entran en la composición de las virtudes como los venenos lo hacen en la de las medicinas. La prudencia los junta y atempera y se sirve de ellos de manera útil contra los males de la vida" (La Rochefoucauld, Réflexions ou sentences et maximes morales, París, 1778, Máxima 182) 
y la obra más temprana de Mandeville apuesta por el hecho de que los beneficios sociales provienen únicamente del deseo de satisfacer el vicio mayor de la complacencia vanidosa que proporciona el orgullo. Pero en un segundo paso en el Diálogo Segundo de la segunda parte de La fábula, Mandeville distingue entre el amor a sí mismo (self-love) y el apego a sí (self-liking) y considera que nos componemos con ambos términos, pero que en las sociedades complejas el segundo es el dominante. El apego a sí es el gusto que encontramos por vernos alabados; pero es algo más complejo que la mera vanidad, tal y como Mandeville trata de explicar, porque no es sólo que deseamos ser alabados por, pongamos por caso, nuestra desprendida generosidad pero seguimos siendo internamente unos avaros, sino que nos complace comprendernos como generosos y en ese momento, aun actuando en un inicio hipócritamente llegamos a olvidarnos de nuestro natural tacañería y no podemos sino complacernos cuando nos consideramos a nosotros mismos como generosos (y actuamos en consecuencia). La hipocresía que es la base del mundo del orgullo y la vanidad, se transforma y deja de ser tal hipocresía: el individuo actúa sinceramente. Es bien cierto que lo hace por un deseo de ser bien considerado, pero ello, se podría decir, no sólo "engaña” a los demás, sino también a sí mismo. Los vicios privados (por ejemplo, el deseo egoísta de ser generoso para ser apreciado y no por algún tipo de virtud natural) tornan en bien público en el momento en que incluso la actuación egoísta se convierte naturalmente en parte de la propia construcción de la identidad. El mero cultivo de la buena educación social que podemos lograr con la vanidad y el orgullo no es suficiente pues en cualquier momento, cuando estuviéramos fuera de la vista de los demás podríamos traicionar toda la sociabilidad. Sólo el apego a sí nos hace sociables en todo momento; incluso cuando no tenemos sociedad ninguna ${ }^{8}$.

Somos egoístas, es cierto, pero inevitablemente sociales y ya no es que seamos capaces de renunciar a algo que nos interesa para que otros nos alaben (lo cual era la propuesta de La Rochefoucauld), sino que realmente llegamos a no reconocernos sino en esa imagen que queremos proyectar a los demás a fin de encantarles (para lo cual, es evidente, debemos renunciar a nuestras pasiones más dañinas socialmente por más que inicialmente nos parezcan irrenunciables). Que construimos nuestra identidad desde la búsqueda de lo que más nos place pero que nos construimos socialmente (i.e., que lo que buscamos como lo que más nos place no es necesariamente lo que nos complace originalmente) es

\footnotetext{
${ }^{8}$ Hector Monro, The Ambivalence of Bernard Mandeville, Oxford University Press, 1975, p. 1267. En este mismo libro se puede encontrar una muy buena explicación del modo en como funciona el apego a sí para construir nuestro mundo social (en el capítulo titulado "The psychologist"). Para el mismo caso excelente es también el capítulo que a Mandeville se dedica en Makku Peltonen, The duel in Early Modern England. Civility, Politness and Honour, Cambridge, Cambridge University Press, 2003.
} 
afirmación de Mandeville que la Ilustración escocesa asume recogiendo el campo de juego que aquel marcó. Y lo asume con algo que se expresa bien en la obra de Hume: la moral es un asunto tremendamente social y posiblemente incluso el egoísta más egoísta necesita de los ojos de los demás.

\section{La presentación del sentido moral por parte de Hutcheson}

El sentido moral será la apuesta escocesa para asumir que somos inevitablemente sociales y que, además, el interés ha de jugar su parte en el mundo moral $^{9}$. En este sentido Mandeville ya había dado el paso: es cierto que sólo pensamos desde nuestro amor a nosotros mismos, pero también lo es que nos amamos más cuando los demás más nos aman (el mundo moral no se ensimisma en el egoísmo). El hecho de necesitar de la mirada ajena ya remarcaba la necesidad de un ámbito social y de un espacio donde recibiéramos - como sensaciones claras y evidentes- esa sociabilidad, ese amor y admiración ajenos. A partir de Mandeville, aunque bien es cierto que hablando contra Mandeville, los escoceses tomaron como obvia la existencia de un sentido mediante el cual recibiéramos -sintiéramospercepciones producidas en tal ámbito moral. Ese fue el sentido moral que permitió que las pasiones se convirtieran en sentimientos. Estos, siendo también naturales y no racionales como lo eran las pasiones, podían ser educados y cultivados.

Fue Hutcheson quien primero propuso esa noción de sentido moral que estiraba a Shaftesbury con la cuerda de Locke; y ello supuso que la elegante sociabilidad caballerosa se convirtió en un sentido que recibía la realidad como cualquier otro sentido (pequeñas percepciones que se unen para formar precepciones más complejas, y de ahí ideas morales o de otro tipo). Realmente el sentido moral es un sentido al igual que el de la vista o el oído. Sólo le diferencia que, como el sentido de la belleza, es un sentido interno. Pero el modo de funcionamiento es el mismo: ante una acción el sentido moral (como el sentido de la belleza) se afecta automáticamente en todos los seres humanos; si tal afección es placentera, aprobamos la acción de la que procede, si no lo es la desaprobamos. Para Hutcheson las acciones que se encaminan al bien público -las acciones benevolentes- complacen de modo universal al sentido moral con lo que es fácil determinar qué es lo bueno y qué no sin hacer llamamiento

\footnotetext{
${ }^{9}$ Un mundo moral que se va a entender - pace Shaftesbury- en los términos de Locke, quien prestaba una perspectiva más conveniente al posibilitar entender la moral con un esquema igual al del conocimiento científico (que es, por otro lado, lo que todos los escoceses quisieron hacer, una ciencia del hombre que partiera de las sensaciones para construir ideas más complejas). Será el sentido moral, como veremos, el instrumento biológico con el cual podemos tener las sensaciones morales con las que se ha de componer la estructura moral del mundo humano.
}

Araucaria. Revista Iberoamericana de Filosofia, Política, Humanidades y Relaciones Internacionales, año 20, $\mathrm{n}^{\circ} 40$. Segundo semestre de 2018. Pp. 311-332. ISSN 1575-6823 e-ISSN 2340-2199 doi: 10.12795/araucaria.2018.i40.14 
a ningún argumento racional ni teológico ${ }^{10}$ : aprobamos tan automáticamente como distinguimos un sonido de mayor volumen o el color rojo.

No es este el momento para exponer las características del sentido moral hutchesoniano ${ }^{11}$, pero sí para hacer un rápido apunte y subrayar dos implicaciones de la apuesta por tal noción. El apunte: la noción de sentido moral es la que en verdad uniforma a toda Escocia y Hume no es ninguna excepción. Con tal noción se puede hablar sin metafísica sobre el mundo moral pues estamos trabajando con sensaciones y componiéndolas del mismo modo en como hacemos con el resto de los sentidos.

La primera implicación que quiero mencionar es que el mismo Hutcheson mostró que existen acciones que se hacen con algún interés egoísta pero que no dejan de generar bien público (o al menos no generan mal a los demás), con lo que podemos tener una aquiescencia del sentido moral, un placer moral, ante acciones que se hacen con un egoísmo "razonable". De este modo ya podemos admitir sin problema que en esas acciones que aprobamos moralmente de manera universal ha habido un interés propio, con lo que evitamos calificarlas de viciosas o de haber sido realizadas en función de los vicios privados. La palabra vicio no cabe cuando el sentido moral está aprobando lo que allí se realiza. Lo que aprueba es virtuoso.

La segunda implicación que quiero señalar aparece cuando se hace evidente que hay que señalar hasta qué punto se puede considerar el egoísmo, el interés propio, sin que la acción caiga en el vicio moral (como señaló Butler hay que aclarar cuál es el amor propio razonable). En este punto Hutcheson propone que aunque el sentido moral responde de modo autómatico, este automatismo no tiene por qué ser inmediato, sino que la pasión moral puede verse demorada siquiera un instante para calmarse y acceder a razones. De este modo aunque el sentido moral no es racional, la argumentación moral, la reflexión, puede modificar su respuesta a ciertas sensaciones. Ello supone un lugar donde las pasiones desbocadas pueden ser sosegadas y ese será el auténtico campo de juego del mundo moral para los escoceses, el de las calm passions. Acontece con el mundo moral lo mismo que con el de las sensaciones estéticas ${ }^{12}$; la respuesta por parte del sentido moral ante una acción siempre es tan automática como pasional, el placer o el displacer, pero cabe que nuestras pasiones se sosieguen y aun respondiendo sin la razón,

${ }^{10}$ El mismo Hutcheson que edifica toda su obra bajo la comodidad del buen creyente, consideró que no hacía falta creer en Dios para ser un hombre virtuoso tal y como se puede comprobar en la sección VI de Illustrations que se titula "Hasta qué punto es necesario tener en cuenta a la Divinidad para hacer una acción virtuosa" (F. Hutcheson, Illustrations on the Moral Sense (edición de B. Peach), Cambridge, The Belknap Press of Harvard University Press, 1971).

${ }^{11}$ Para ello se puede consultar mi introducción a F. Hutcheson, Escritos sobre la idea de virtud y sentido moral, Madrid, Centro de Estudios Constitucionales, 1999.

${ }^{12}$ Este es un paralelo bajo el cual quiero terminar este trabajo que tiene su origen ya en el primer libro de Hutcheson, Inquiry into the Original of Our Ideas of Beauty and Virtue. 
puedan acceder a sus razonamientos, sus historias, sus cuentos, etc., lo cual conformará un proceso de afinamiento, de educación, de civilización moral, que intentaré subrayar cuando a continuación hable de Hume. Es un proceso por el cual la pasión se convierte en sentimiento (y un sentimiento no es sino una sensación, no se olvide).

Eso sí, estamos hablando de un sentido y por ello las razones que aporta la razón pueden tomarse como reflexiones, como cauciones, como adecuaciones, pero no son ni concluyentes ni la última. Sí son afinamientos, relatos con los que componemos todo lo que vamos a entender como bien público o benevolencia. Realmente, la benevolencia no es algo natural del hombre ${ }^{13}$, lo que sí es natural es el sentido moral. Pero es necesario adquirir la benevolencia para complacer a ese sentido moral y, tal adquisición, se hace sólo de una manera, a saber, educando e ilustrando aquel ámbito que vimos de las pasiones sosegadas a través de un calmado diálogo entre la razón y las pasiones ${ }^{14}$.

¿Diálogo calmado? Bien, entenderemos correctamente este ámbito si lo imaginamos como la educación que se establece basándose en relatos morales, en ejemplos, en buenas compañías también ${ }^{15}$. No es extraño que la más alta virtud, la benevolencia hacia los enemigos y el amor a los malvados, sea, más que un objetivo de la moral, un hito de santidad que se cuenta como límite máximo al cual aspirar. Son precisamente esos hitos, esos relatos del máximo bien en definitiva, los que valen para la promoción de la benevolencia que, de este modo, no sólo nos está diciendo "haz el bien público", sino que está creando una serie de narraciones en los que ese bien público se ve contado. Y con ello se ve establecido. Como afirma Purviance, "la imaginación-cultivada por la literatura, la poesía y el discurso- ayuda al sentido moral proponiéndole objetos de beneficencia cada vez más extensos"16. Y todo ello sin olvidar que "al igual que otros de nuestros poderes perceptivos inmediatos son capaces de cultivo y mejora, así lo es el sentido moral, sin presuponer ninguna referencia a un poder superior de la razón al que se refieran sus percepciones"17. Aquí es donde aprendemos a percibir alguna dosis de egoísmo dentro de la acción sin que ello ofenda a nuestro sentido moral.

${ }^{13}$ T.A. Roberts, The Concept of Benevolence. Aspects of the EighteenthCentury Moral Philosophy, Londres, MacMillan Press, 1973, p. 13.

${ }^{14}$ Cfr. S. Darwall, The British Moralist and the Internal 'Ought': 1640-1740, Cambridge University Press, 1995, pp. 226-228.

${ }^{15}$ Es de destacar que mientras Shaftesbury por regla general usaba el término razón, Hutcheson siempre utiliza el término reflexión poniendo claro que el campo de juego de las pasiones sosegadas sin ser enteramente racionales no es irreflexivo.

${ }^{16}$ S.M. Purviance, "Intersubjetivity and Sociable Relations in the Philosophy of Francis Hutcheson" en EighteenthCentury Life, no 15, FebreroMayo de 1991 (2338), p. 35.

${ }^{17}$ F. Hutcheson, System of Moral Philosophy, 1, 4, V, p. 59 [la cita corresponde a la edición facsimile de F. Hutcheson, Collected Works, Hildesheim, Georg Olms, 1969-1971].

Araucaria. Revista Iberoamericana de Filosofia, Política, Humanidades y Relaciones Internacionales, año $20, \mathrm{n}^{\circ} 40$. Segundo semestre de 2018. Pp. 311-332. ISSN 1575-6823 e-ISSN 2340-2199 doi: 10.12795/araucaria.2018.i40.14 


\section{La propuesta de Hume}

Si bien es cierto que la idea de un sentido moral es tomada por toda la Ilustración escocesa, nadie la vinculará tan inmediatamente con el bien público como originalmente lo hizo Hutcheson. Sería Hume quien primero planteó que tal vínculo no deja de ser un deseo de pintor que no se corresponde con el verdadero funcionamiento de la anatomía moral humana ${ }^{18}$. Pues aunque el mundo moral no es algo propio de la razón (lo cual no supone que sea irracional, por supuesto) y parece lógico buscar su acomodo en el espacio de un sentido moral, lo cierto es que no es fácil decir que este se complazca siempre, sólo e inmediatamente con las acciones encaminadas directamente al bien público. La distancia, sin ir más lejos, apunta Hume nos haría indiferentes hacia acciones benevolentes de las que no tenemos noticia o no nos causaría un displacer enorme aquellas acciones viciosas ocurridas en algún país lejano o en mi propio país con personas a quienes no conozco. Además, qué duda cabe de que la cercanía afectiva me hace ser más tolerante con las acciones no benévolas.

El problema del sistema de Hutcheson, como apuntarían rápidamente Hume, Smith y todos los literatti escoceses, es que resulta válido para sociedades pequeñas, tan caballerosas como las que Shaftesbury tenía en mente, pero en una sociedad comercial cuya definición misma es la complejidad y amplitud de relaciones es difícil pensar que todo comportamiento no benevolente me cause inquietud. Es más: puestos a admitir alguna dosis de egoísmo en el mundo de la virtud moral (en los lugares que complacen al sentido moral), hay que reconocer que puede haber muy distintas recetas para componer venenos y obtener medicinas sociales.

En el caso particular de Hume hay que decir que él tenía problemas con la noción de benevolencia pues consideraba que naturalizaba a conveniencia las pasiones morales. Si bien es cierto que podía admitir como algo demostrable que naturalmente nos complacemos con sentimientos benevolentes y de piedad, el hecho de suponer una natural inclinación a obrar bien no le satisfacía en demasía. "No puedo acordar con su sentido de natural. Está fundado sobre causas finales lo cual es un planteamiento que me parece bastante incierto y no filosófico. Pues, entonces, ¿cuál es el fin del hombre? ¿ha sido creado para la felicidad o para la virtud?¿para esta vida o para la ulterior?¿para él mismo

\footnotetext{
18 "Hay diferentes maneras de estudiar tanto el espíritu como el cuerpo. Uno puede considerar tal estudio o como un anatomista o como un pintor; o descubrir los fundamentos y principios más ocultos o describir la gracia y belleza de las acciones. Creo que es imposible unir estas dos perspectivas [...] Un anatomista, con todo, puede dar muy buenos consejos al pintor o al escultor y, de igual manera, estoy persuadido de que un metafísico puede ser muy útil a un moralista; aunque no puedo concebir como estos dos caracteres podrían unirse en el mismo estudio" (D. Hume, The Letters of David Hume (edición de J.Y.T Grieg), 2 vols. Oxford, Clarendon Press, 1932. Carta 13, Julio de 1739. Vol. I, pp. 3233. Se citará a continuación como "Carta").
} 
o para su Hacedor? Su definición de natural depende de la solución de estas preguntas, cosa que es infinita y muy alejada de mi propósito" [Carta].

En realidad, la negación de la benevolencia universal que encontramos en el Tratado se basa casi en una admisión de sentido común: lo que hace que amemos o estimemos a otros no es nuestra naturaleza o nuestra humanidad benevolente, sino cualidades que poseen las personas objeto de nuestro amor y estima ${ }^{19}$. Y esto supone que si es posible admitir algún interés en el relato de la benevolencia siempre y cuando no entorpezca el bien público, se abre la puerta entonces a intereses que si bien no conducen al bien público general tampoco son incompatibles con un bien público más localizado y particular. Se podría decir que en una sociedad compleja hay una diferencia de "públicos" precisamente porque es una sociedad que se ha abierto y dejado paso a otras voces que no son las de los caballeros ${ }^{20}$. En este sentido Hutcheson aportó los elementos para jugar con bien en el campo establecido por Mandeville, pero tales elementos era preciso recomponerlos, ponerlos a delinear estrategias, pases y modos de ataque y defensa imposibles de imaginar en un mundo de caballeros ajeno a la época comercial. Las nociones de sentido moral, de pasiones sosegadas, de benevolencia, de interés en lugar del vicio, se comienzan a organizar, a partir de Hume, de una manera que, efectivamente, ya habla de un mundo netamente moderno. Por no dar muchas vueltas quiero recordar que Hume toma a la benevolencia como una pasión directa al igual que el miedo, la aversión o la alegría ${ }^{21}$ que surge de modo inevitable generalmente referida a quienes nos son cercanos. Ello supone una emoción tan inmediata y poco dominable que difícilmente puede tomarse como una virtud moral que fuera piedra angular de nuestras relaciones sociales. Es una virtud principalísima, es cierto, que, por ejemplo y en la línea de Mandeville, sirve para aminorar el negativo efecto de otras pasiones como la ambición ${ }^{22}$, pero no deja de ser una emoción -no un sentimiento moral- dirigida a quienes nos son cercanos

19 "Ahora bien, no hay nada común entre la belleza natural y la moral (y ambas son causa de orgullo) sino su poder de producir placer; $y$, como un efecto común implica una causa común, es evidente que el placer deberá ser en ambos casos la causa real y eficiente de la pasión. Por otra parte, no existe más diferencia original entre la belleza de nuestro cuerpo y la de los objetos externos, y que nada tienen que ver con nosotros, que el hecho de que la primera clase de belleza está íntimamente relacionada con nosotros, mientras que la otra no lo está. Esta diferencia original deberá ser, pues, la causa de todas las demás diferencias y, entre éstas, de su diferente influencia sobre la pasión del orgullo, que es despertado por la belleza de nuestra persona, pero en cambio no se ve afectado en lo más mínimo por la existente en objetos externos y no relacionados con nosotros" (D. Hume, Tratado de la naturaleza humana (traducción de F. Duque), Madrid, Editora Nacional, 1982. Se citará como Tratado (la paginación respetará la de la edición canónica de L.A. Selby-Bigge: Oxford, Clarendon Press, 1951).

${ }^{20} \mathrm{Y}$ con ello hemos conseguido dejar de referir todas y cada una de nuestras acciones a la benevolencia: "Esto prueba que para cada acción virtuosa debe existir un motivo o pasión motivadora diferente a la virtud, y que la virtud no puede ser el único motivo para toda acción. Usted no acuerda con esto, aunque creo que no hay proposición más cierta e importante" [Carta].

${ }^{21}$ Tratado, II, III, I, p. 399.

${ }^{22}$ Tratado, II, III, III, p. 604.

Araucaria. Revista Iberoamericana de Filosofia, Política, Humanidades y Relaciones Internacionales, año $20, \mathrm{n}^{\circ} 40$. Segundo semestre de 2018. Pp. 311-332. ISSN 1575-6823 e-ISSN 2340-2199 doi: 10.12795/araucaria.2018.i40.14 
y ello la hace demasiado parcial para organizar un mundo donde la mayoría de los individuos no se llegan a conocer (en buena medida ni siquiera llegan a interactuar entre ellos) $)^{23}$.

Los problemas que Hume puede señalar a la benevolencia hutchesoniana son extensibles a buena parte del elenco de virtudes que complacían al padre de la Ilustración escocesa y, llegados aquí, siendo complicado especificar cuáles afecciones morales son universalmente placenteras, la finta de Hume pasa por estudiar el elemento que permite que tal sentido moral pueda funcionar, que pueda siquiera tener afecciones morales compartibles socialmente. Tal elemento no es otro que el mecanismo de la simpatía ${ }^{24}$.

Hume introduce por primera vez la noción de simpatía en el libro II del Tratado con un significado técnico: la simpatía es el proceso por el que una idea se convierte en una impresión ${ }^{25}$. En este sentido, la simpatía nos hace sentir como inicialmente no sentimos y nos permite salir de nuestras primeras impresiones con lo que evitamos el solipsismo moral (lo cual ya se había avanzado con la noción de apego a sí que Mandeville apuntó). Este es el medio para sentir como propia la "desgracia" del extranjero, del que no somos nosotros, para sentir los sentimientos morales que los demás sienten aunque de hecho no los sintamos propiamente ${ }^{26}$.

La empatía trabaja junto con la comparación que la atempera y afina para dar a luz las pasiones del alma. Es un maravilloso mecanismo por el cual se supera al Barroco y a Mandeville pues aquí no es el caso que las pasiones se puedan oponer, sino que, como quiero mostrar, descubrimos la posibilidad de abrir un campo en el que de manera natural las regulamos, modulamos y afinamos. No otro era el ámbito de las pasiones sosegadas que instituyó Hutcheson y que a partir de aquí será el ámbito por excelencia de la reflexión moral y del sentido del gusto pues, como diré al final de mi texto, ambos caminan parejos. Permítaseme otro ejemplo ilustrado con un cuadro de Greuze.

\footnotetext{
${ }^{23}$ Ahora bien, no se debe olvidar que la benevolencia, aun dirigida a nuestros más próximos, tiene una sinergia que afecta a la moralidad en general y sus efectos son contagiosos de modo que si todos fuéramos benevolentes ello redundaría en el beneficio colectivo (Cfr. Tratado, III, III, VI, p. 618-620).

${ }^{24}$ Sympathy es la denominación del mecanismo y considero que "empatía" sería su mejor traducción por más que tradicionalmente se haya vertido al castellano como "simpatía". En lo que sigue usaré ambas traducciones de modo indistinto; con la segunda seguro que el texto resultante no resultará extraño a los oídos del lector; con la primera creo que recuerdo cuál es el modo en como ha de entenderse realmente el concepto de Hume.

25 "Cuando simpatizamos con las pasiones y sentimientos de los demás, estos movimientos se manifiestan al comienzo en nuestra mente como meras ideas, y son concebidos como algo ajeno, igual que cuando concebimos cualquier otro hecho. Es también evidente que las ideas de las afecciones ajenas se transforman en las impresiones mismas que representan, y que las pasiones surgen en conformidad con las imágenes que de ellas nos formamos” (Tratado, II, I, XI, p. 319).

${ }^{26}$ Donde mejor queda explicado lo que psicológicamente ocurre cuando una persona simpatiza con otra es en la sección del Tratado titulada "Del ansia de fama".
} 


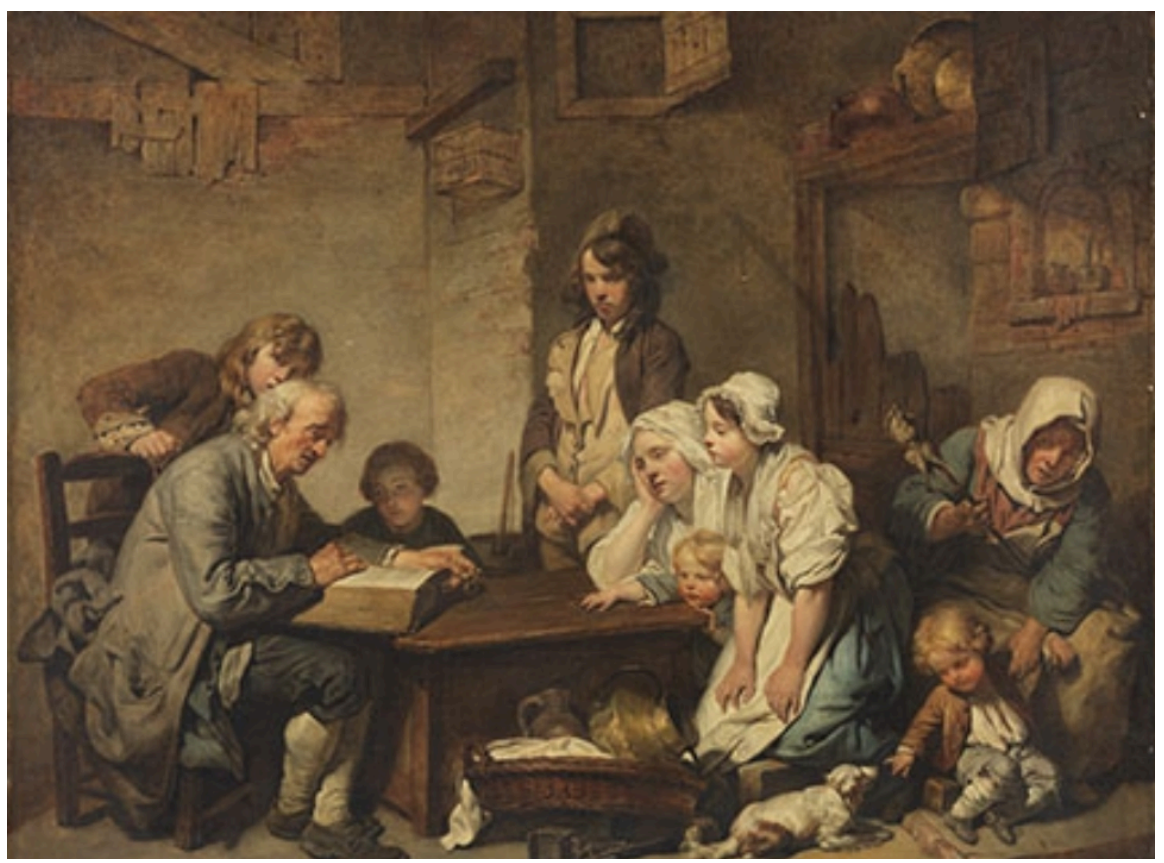

Por más que se busque es difícil encontrar alguna línea que indique las preferencias pictóricas de Hume, pero parece asumido entre los no muchos que han intentado escribir sobre la estética humeana que seguramente sus preferencias estarían al lado de la "escuela francesa". Ello me lleva a imaginar que quizá viera con buenos ojos al pintor que Diderot veía con buenos ojos y que se alzó como respuesta al Rococó (justo antes de que los pintores de la Revolución aparecieran). Como fuere, lo que me interesa subrayar del cuadro de Greuze es su melifluo sentimentalismo que hace que nos identifiquemos con una escena moral que bien podríamos tomar como un estimulante de la benevolencia (un maestro que se toma un trabajo en enseñar a algunos menesterosos en las condiciones menos ideales). Lo que aquí se excitan son también nuestras pasiones, pero estas se encuentran a años luz de las imágenes de Gargantúa. Son mucho más civilizadas. Hay en la escena un algo que nos hace empatizar moralmente con ella. Y sentir cierto placer. Posiblemente los personajes que intervienen nos queden tan lejanos como Gargantúa, mas ante Greuze sentimos un movimiento de identificación que nos hace sentir de un modo general la misma inclinación hacia esa escena. Y ello no es ningún deseo de pintor, sino algo comprobable empíricamente por cualquier anatomista que aplique su estudio al mecanismo natural de la simpatía. No hace falta darle 
muchas vueltas: pasiones, sí, pero indudablemente mucho más urbanizadas que las que aparecían con el grosero relato de Rabelais.

\subsection{La experimentalidad de la simpatía}

En verdad es un mérito de la simpatía que nunca necesita explicarse en términos de un propósito humano o de una naturaleza humana. Frente a la benevolencia que es más bien un compartir un lugar -una comunidad-, la simpatía, como principio que explica de qué modo sentimientos y opiniones pueden pasar de un individuo a otro, es un mecanismo necesario que comunica nuestros sentimientos morales. Es una mecánica comunicativa por la que la idea se convierte en pasión y mueve a actuar: si percibo que otro tiene ansiedad, por ejemplo, lo que tengo es la idea de que otra persona tiene un comportamiento ansioso. Pero tal idea no me movería hasta tanto por el misterioso mecanismo de la simpatía no se convirtiera en una impresión, en una verdadera pasión que me hace sentir la ansiedad ajena ${ }^{27}$.

Los méritos de comprender el sentido moral en términos de simpatía son que esta puede explicarse de modo experimental como un revivir de nuestras ideas cuando nos encontramos a nosotros mismos en asociación con otras personas que están conectadas con nosotros por proximidad, causalidad o semejanza $^{28}$. Realmente la simpatía es un mecanismo psicológico que puede convertir una idea en una impresión de modo que adquiera un mayor grado de fuerza y vivacidad ${ }^{29}$; de este modo es posible que ideas (morales en este caso) se conviertan en una experiencia sentida, con vivacidad, con lo que de alguna manera la empatía permite recorrer a la inversa el camino del conocimiento: las ideas complejas se pueden tornar sensaciones -efectivas-. Como se ve, si bien es innegable que el placer ante una acción supone el origen de nuestra aprobación de la misma, ello no saldría de nuestro particular sentido moral; merced a la empatía nos contagiamos de los sentimientos de los demás y la apuesta por los sentimientos morales puede conformar sociabilidad ${ }^{30}$.

En este punto se podría pensar que la simpatía, en tanto comunicación de los sentimientos morales, bien podría suplantar a la benevolencia. El

${ }^{27}$ Philip Mercer, Sympathy and Ethics, Oxford, Clarendon Press, 1972, p. 26

${ }^{28}$ De hecho el concepto de simpatía no estaba muy lejano a las observaciones empíricas de la psicología: "Ni en sí misma ni en sus consecuencias existe cualidad de la naturaleza humana más notable que la inclinación que tenemos a simpatizar con los demás, y a recibir al comunicarnos con ellos sus inclinaciones y sentimientos por diferentes y aun contrarios que sean a los nuestros" [Tratado, II, I, XI, p. 316]

${ }^{29}$ Tratado, II, I, XI, p. 317.

30 "El compromiso de Hume con el sentimentalismo se funda en su observación de que nuestras respuestas empáticas tienen el efecto real de provocar que tomemos el bienestar o la desgracia ajena como una cuestión que nos concierne a nosotros mismos" (Hans D. Muller, "Hume on Sympathy, Pity and Impartiality" incluido en G. Boros, J. Szalai \& O.I.Tóth (eds.), The Concept of Affectivity in Early Modern Philosophy, Budapest, 2017, p. 259). 
problema aquí es que a la noción de simpatía le falta la universalidad que tenía la benevolencia; la simpatía se debilita, entra en el mundo de lo contingente, tiene grados y momentos en que se oculta intencionadamente. Si fuera la única fuente de la obligación moral resultaría que, por ejemplo, la autoridad o los derechos de propiedad podrían caducar a poco que se debilitara u ocultara la simpatía. Por eso Hume ha de enfatizar que la obligación interesada es la base de la sociedad y siendo ello así la simpatía es el ingrediente imprescindible de una obligación moral que se soporta en el interés ${ }^{31}$.

Se debe observar aquí el cambio que introduce Hume con respecto al sentido moral benevolente de Hutcheson y la respuesta al proyecto Mandeville. El cambio que el sentido moral de Hutcheson experimenta: ya no es afectado agradablemente de modo inmediato por las acciones encaminadas al bien público, sino que el placer o el displacer acceden al sentido moral mediados por intereses, distancia, etc. Realmente la simpatía es un muy poderoso principio de la naturaleza humana ${ }^{32}$ y como tal principio lo podemos conocer por su operatividad constante y uniforme. Por ello podemos inferir con justicia (como en cualquier otra cuestión de hecho ${ }^{33}$ ) desde la observación del comportamiento de la experiencia de ciertas pasiones, que existe un principio que nos saca de nosotros de modo que nos puede placer o disgustar el placer o displacer de los demás ${ }^{34}$. Así, aun sin ser un sentimiento moral -como lo hubiera sido en Hutcheson- la simpatía es básica en la producción de nuestros sentimientos morales ${ }^{35}$.

\subsection{La sociabilidad del sentido moral}

Contra el mundo del Gargantúa-Mandeville, para Hume las pasiones no son las fuerzas divisorias que amenazan el orden social, sino la necesaria moneda para la sociabilidad: la pasión no es un apetito, sino un sentimiento

\footnotetext{
${ }^{31} \mathrm{El}$ naturalismo de Hutcheson, que con grandes dosis de realismo niega Hume, hacía inconcebible que nuestra naturaleza humana nos pudiera conducir al vicio. Somos seres creados por Dios y el vicio sólo podrá avenirnos como una perversión de nuestra benévola y pura naturaleza. La postura más realista de Hume es simplemente su admisión de que nuestra naturaleza nos puede conducir tanto al bien como al mal.

32 "La simpatía es un principio muy poderoso en la naturaleza humana, que tiene gran influencia en nuestro sentido de la belleza y que origina el sentimiento moral en todas las virtudes artificiales. Partiendo de estos puntos, cabe suponer que la simpatía origine también muchas de las restantes virtudes y que sea la tendencia al bien de la humanidad lo que haga merecedora de nuestra aprobación a una cualidad mental" (Tratado, III, III, I, p.577). Ver también Tratado, III, III, VI, p. 618.

${ }^{33}$ Cfr. Tratado, II, I, XI, p. 319.

34 "No tenemos una preocupación tan amplia por la sociedad más que en virtud de la simpatía, $\mathrm{y}$, por consiguiente, es este principio el que nos pone tan fuera de nosotros mismos que hace que el carácter de los demás nos produzca el mismo placer o desagrado que si mostrara una tendencia a favor o en contra de nuestro propio provecho" [Tratado, III, III, I, p. 579].

${ }^{35} \mathrm{Y}$ además, "la simpatía constituye el origen del aprecio que experimentamos hacia todas las virtudes artificiales" [Tratado, III, III, I, p. 577].
} 
que cuando es comunicado merced al mecanismo psicológico de la empatía, crea sociabilidad. Porque en realidad Hume pensaba que "una persona es responsable de su disposición emocional tan sólo en la medida en que, a través de nuestra humana capacidad común para simpatizar con otros, afectamos a los demás y, de aquí, afectamos a sus sentimientos morales" "36, por ello podemos concluir que realmente es por compartir los sentimientos morales como podemos imaginar una sociedad.

Por seguir en el campo de juego de Mandeville: podríamos decir que el paso del mecanismo del "apego a sí" al mecanismo de la simpatía es fundamental. Y lo es porque sentir lo que otros sienten (en puridad: lo que creemos que otros sienten) supone extender el plano de la acción moral de un modo que excede el mero apego a sí (el deleite consigo mismo). Es una forma de desterrar el concepto de "vicio egoísta" porque no soy yo que me miro en los ojos de los demás, sino que soy yo que siento el dolor o placer que imagino que otros tienen. Es preciso advertir que la simpatía no es un mecanismo que se ponga en marcha cuando alguien apriete un botón, es más bien una mecánica, un proceso de comunicación y en este punto la imaginación es un elemento que introduce la posibilidad de algún manejo razonable de la situación moral: el contagio no es inmediato desde el placer o displacer ajeno, sino que lo imagino y la empatía es capaz de dar vida a tal imaginación. Hablamos de pasiones, es verdad, pero tremendamente mediadas y es la simpatía la herramienta que permite conformar el ámbito de esa mediación que no es otro sino el de las pasiones sosegadas. De este modo la razón puede ser esclava de las pasiones, pero estas no son irracionales porque en el campo de las pasiones sosegadas se gestiona con cierta reflexión las emociones que, de tal modo, se convierten en sentimientos. Tan sólo miremos de nuevo las ilustraciones del Gargantúa y el cuadro de Greuze para darnos cuenta del campo de sosiego y urbanidad que se ha ganado aquí para las pasiones.

Algo no ha de pasarse por alto: la simpatía es un mecanismo y no una pasión ni tampoco es benevolencia. Un mecanismo que supone una fácil comunicación de sentimientos por los que uno se complace con aquello que complace a otro ${ }^{37}$ y que salta el solipsismo emocional de Mandeville (el "egoísmo vicioso" podríamos decir) en la medida en que implica comunidad. Una comunidad donde el interés es posible. Todo ello apunta al hecho de que, como se ha observado en varios lugares, la moral de Hume es sobre-socializada hasta el punto de que se podría afirmar que el individuo considerado en sí mismo no es fundamental en el mundo moral humeano -aunque sí que lo es el individuo

${ }^{36}$ Paul Russell, Freedom and Moral Sentiment. Hume's Way of Naturalizing Responsability, Oxford University Press, 1995, p. 116-7. En este sentido la sección 71 de la segunda Investigación es tan clara como reveladora (también lo es la sección 9).

${ }^{37}$ Cfr. Tratado, II, II, V, p. 554 
empatizando $^{38}$ - . De hecho la idea de Hume no es que nos identifiquemos con el otro aun siendo nosotros mismos sino que la empatía implica "una especie de olvidarse de la individualidad como si uno tomara a su cargo los sentimientos de otra personas y de alguna manera se convirtiera en esa persona en el proceso" ${ }^{\prime 39}$. Así no es extraño que mi sentimiento de la pena o alegría ajena puede ser mayor que el sentimiento de mi propia pena o alegría ${ }^{40}$. Al igual que sucedía en el caso de Hutcheson, sólo hay moralidad en el intercambio que supone el sentido moral y esto es posible mediante el evidente mecanismo natural de la empatía.

La sociabilidad que apareja la empatía y el mismo sentido moral (que es, repito la sociabilidad que aparece con el "apego a sí" aunque bien es cierto que transforma la identidad en un proceso contextual y comunitario que Mandeville no había planteado) es tan profunda que incluso aparece la posibilidad de que podamos sentir placer al empatizar con las desgracias ajenas aun en el caso de que empaticemos con su dolor y sea la pena lo que se contagie. Ello es posible porque el proceso de la simpatía nos proporciona una sensación secundaria, a saber, el hecho de que empatizamos con otro lo cual nos da el placer del amor y la benevolencia ${ }^{41}$. Como apunta Taylor, aquí Hume recoge el legado del sentido moral y la benevolencia: de alguna manera sentirnos juntos da placer ${ }^{42}$.

La simpatía entendida como un mecanismo psicológico es más que un mero mecanismo, es un proceso psicológico por el cual "experimentamos una versión de la misma emoción que suponemos tiene otra persona"43. Lo cual no es un mero contagio de la emoción ajena, sino una emoción nuestra que nos nace con un ejercicio del proceso de pensamiento. $\mathrm{Y}$ debemos recordar que hablamos de un mecanismo que no es automático o "pasional", sino que exige un esfuerzo de nuestra voluntad, una querencia pues no es el caso de que nos afectemos cuando vemos el dolor ajeno, sino que podemos formarnos un sentimiento del dolor cuando nos formamos la idea de eso que ha de doler o ser $\mathrm{cruel}^{44}$. No creo que haga falta subrayar aquí la fuerza de la imaginación ${ }^{45}$; pero nada saldría de la propia cabeza, de lo que "yo creo que siente el otro" sin ese mecanismo psicológico que permite que yo sienta realmente las emociones de otro: "tu alegría puede convertirse en mi alegría y tu pena puede hacerlo en mi

${ }^{38}$ Gerald J. Postema, “Cemented with Diseased Qualities': Sympathy and Comparision in Hume's Moral Psychology” en Hume Studies, Vol. 31, n² 2, 2005 (249-298), p. 257.

39 James Harris, Hume: An Intellectual Biography, Cambridge: Cambridge University Press, 2015 , p. 110.

${ }^{40}$ Tratado, II, I, XI, p. 317.

${ }^{41}$ Tratado, II, II, IX, pp. 384-6.

42 Jacqueline Taylor, Reflecting Subjects: Passions, Sympathy, and Society in Hume's Philosophy, Oxford, Oxford University Press, 2015. Cfr. también el ensayo "On National Characters" (D. Hume, Essays Moral, Political, and Literary (edición de E.F. Miller), Indianapolis, Liberty Fund, 1985, p. 202 [D. Hume, Ensayos morales, politicos y literarios, Madrid, Trotta, 2011, p. 200]).

${ }^{43}$ H.D. Muller, Op. Cit., p. 215.

${ }^{44}$ Tratado, II, II, II, pp. 333-338.

${ }^{45}$ Gerald J. Postema, Ibid. p. 259.

Araucaria. Revista Iberoamericana de Filosofia, Política, Humanidades y Relaciones Internacionales, año $20, \mathrm{n}^{\circ} 40$. Segundo semestre de 2018. Pp. 311-332. ISSN 1575-6823 e-ISSN 2340-2199 doi: 10.12795/araucaria.2018.i40.14 
pena. Tu experimentación de esas emociones puede convertirse en la causa, si es mediada por la empatía del modo correcto, de mi experimentación de esas emociones" ${ }^{46}$.

Quizá no estemos aquí con un proceso racional que se contenta con planteamientos y respuestas de la mera razón, pero sí que estamos en un ámbito lo suficientemente reflexivo y mediado como para no ser emocional, pasional en el sentido que podría entender Mandeville. Es este el ámbito de las pasiones sosegadas donde ha de caber cierta educación y refinamiento y donde, por supuesto, nos podemos olvidar de Gargantúa y sentir civilizadamente con Greuze.

\subsection{El afinamiento moral}

Lo interesante de apostar por el mecanismo de la simpatía es que con él tenemos la respuesta de Hutcheson a Mandeville (es decir, podemos transformar el vicio en interés e introducir este en nuestra concepción moral), pero sin caminar por los pagos del pintor. A través de un mecanismo psicológico de evidencia y comprobable empíricamente se consigue un estado de sociabilidad que puede ser educado o, si se prefiere, refinado. No de modo racional, es cierto, mas si calmada, reflexiva y razonablemente. Es esto último lo que quiero subrayar en este momento, pero antes no se debe pasar por alto el definitivo olvido del mundo del barroco: las pasiones no son desatadas y podemos olvidarnos de luchar contra ellas oponiéndolas otras pasiones. Rabelais no tiene ningún sentido en la Modernidad que Hume presenta. Aunque tampoco lo tiene seguir creyendo en una benevolencia cristiana o caballeresca cuando vivimos en un mundo que ya es enteramente comercial. Otrosí: Hume siente gran desconfianza por toda aquella apuesta por los poderosos poderes de la humanidad o de la razón que tienen más de deseo de pintor que de evidencia anatómica.

Para continuar quiero recordar que la imaginación es fundamental para que la empatía convierta en sentimiento una idea siendo realmente el fundamento de casi todas las virtudes derivadas; así, por ejemplo, la piedad acontece cuando por algún extraño giro de la imaginación sentimos hacia otro lo que solemos sentir hacia nuestros cercanos. Y algo similar ocurre con la malicia. Mas algo es evidente: la imaginación no funciona de modo automático, sino que requiere de un esfuerzo. En este sentido podemos esforzarnos imaginativamente en tener una reacción benevolente desde la simpatía aunque bien es cierto que -y aquí Hume oficia contra el pintor- tendremos éxito en alcanzar un comportamiento benevolente sólo si nos favorecen las circunstancias. Es este un esfuerzo que en definitiva persevera en una sociabilidad formada desde un mecanismo que

${ }^{46}$ H.D. Muller, Op. Cit., p. 264.

Araucaria. Revista Iberoamericana de Filosofia, Política, Humanidades y Relaciones Internacionales, año $20, \mathrm{n}^{\circ} 40$. Segundo semestre de 2018. Pp. 311-332. ISSN 1575-6823 e-ISSN 2340-2199 doi: 10.12795/araucaria.2018.i40.14 
es natural, eso sí, pero no produce universalidad. Ese perseverar es lo que da el talante moral de cada quien. Y ese perseverar, al final no es otra cosa que refinar el proceso y los motivos de la simpatía lo cual se hace de modo semejante a como se agudiza y afina el gusto.

Resulta relevante, cuando se tiene en la cabeza la idea de las pasiones sosegadas (en las que el vicio se transforma en interés), leer el ensayo "De la norma del gusto". Allí aprendemos que sin tener nunca una última razón, lo cierto es que nadie preferiría a Ogilby antes que a Milton. ¿Cómo se llega a esta evidencia prácticamente suscrita de modo universal? Hume señala cinco cualidades en la conformación del gusto por parte de aquel que puede ser señalado como un crítico refinado (el equivalente a un hombre virtuoso): (a) un sentimiento delicado, (b) cierta práctica en el mundo de la estética, (c) la habilidad para hacer comparaciones, (d) una mente libre de prejuicio y (e) un sentido firme afianzado por la reflexión.

Para empezar con la primera de esas cualidades, la delicadeza (a), hay que decir que esta no es sólo saberse tocar por la obra de arte, sino poder recoger sutilizas más o menos complejas en la misma. Ello es en buena medida lo que se realiza con el afinamiento de la empatía: poder ser empático con cada vez más gente o al menos con aquella gente que en un principio no tiene relación con nosotros. La delicadeza es el atributo del crítico de gusto que equivale al carácter en las cuestiones morales: el buen crítico siempre acierta, el buen carácter moral siempre suele actuar de modo virtuoso. Siendo esto claro, debemos ser conscientes de que aunque la capacidad para ser afectado por la belleza es propia de nuestra naturaleza humana, es evidente que puede ser afinada y mejorada por la experiencia, por lo que Hume llama la práctica (b). Del mismo modo que el sentido moral se establece desde el mecanismo de la simpatía y ello conforma un espacio, el de las pasiones sosegadas, que es el verdadero campo de juego del talante moral, en las cuestiones de gusto la delicadeza se afina con la práctica que tiene contacto con obras de arte "desde distintos puntos de vista con atención y deliberación" 47 de modo que impresiones que inicialmente podían ser confusas y oscuras después de ser repetidas la sensibilidad hacia ellas "se hace más precisa y refinada" 48 : aprendemos a admirarlas. Acostumbrar el gusto a las cosas que ha de juzgar, enseñarle que hay más de lo que en un inicio se percibe, esta es una práctica que supone (c) hacer comparaciones entre diferentes especies y grados de belleza: "mediante la comparación establecemos los epítetos de alabanza o reproche, y aprendemos a asignarlos en el debido grado"49.

${ }^{47}$ D. Hume, Essays Moral, Political, and Literary (edición de E.F. Miller), Indianapolis, Liberty Fund, 1985, p. 238 [D. Hume, Ensayos morales, politicos y literarios, Madrid, Trotta, 2011, p. 228]).

${ }^{48}$ Ibid., p. 237 [p. 228].

${ }^{49}$ Ibid., p. 238 [p. 228].

Araucaria. Revista Iberoamericana de Filosofia, Política, Humanidades y Relaciones Internacionales, año 20, ${ }^{\circ} 40$. Segundo semestre de 2018. Pp. 311-332. ISSN 1575-6823 e-ISSN 2340-2199 doi: 10.12795/araucaria.2018.i40.14 
Todo lo anterior supone un esfuerzo. Hablamos de pasiones y de instintos naturales, pero que han de trabajar calmadamente, que han de hacer comparaciones, experimentar cosas diferentes y en este sentido es lógico que (d) a fin de formar un "verdadero juicio" un crítico debe imponer una cierta violencia sobre su imaginación ${ }^{50}$ de modo que pueda elevarse sobre algunos prejuicios iniciales y tenga la voluntad de establecer nuevas prácticas y comparaciones. Se trata en este punto de tener una disciplina que evite juzgar una obra anticipadamente o por inclinación hacia su autor o la audiencia que le favorece. Es lógico, tras todo lo dicho, que (e) debemos dar por sentado un buen sentido en lo que refiere al gusto que Hume identifica con la razón y el juicio. No es que gustemos de lo que nos indique nuestra razón, pero esta sí que nos puede ayudar a obviar prejuicios, a establecer comparaciones y a discernir relaciones complejas en la obra. Todo ello hará más delicado -afinado- nuestro gusto y nos hace evidente que la razón entra en un ámbito donde ayuda a los sentimientos del gusto como también podía ayudar a los sentimientos morales. Aun siendo diferentes sentidos, el moral y el del gusto, plantean campos donde se juega de modo igual y en los cuales la razón es un elemento más que hace que aunque no enteramente racional, el juicio de gusto, como el juicio moral, no sea, por supuesto, irracional ${ }^{51}$.

En el juicio de gusto convertimos en impresión la idea de equilibrio, naturalidad, conveniencia, etc. Y para ello es fundamental una educación que nos proporcione esas ideas, sea la de equilibrio o naturalidad, de modo adecuado. Del mismo modo los sentimientos morales convierten ideas en impresiones que nos hacen sentir con los demás. Lo interesante es que en ambos casos se construye un ámbito de sociabilidad, de moralidad si se quiere, en el que nos es evidente quien es Milton y quien es Ogilby. No quiero decir ahora que juicio de gusto y juicio moral estén imbricados uno en el otro, no es que uno necesite del otro, pero sí que creo que es evidente que ambos funcionan de la misma manera y proporcionan, uno al otro, modelos de comprensión de la actividad moral y estética. Nada raro debe parecernos esto si pensamos en que el juicio moral y el juicio de la belleza se desarrollaban también de modo paralelo, de modo yuxtapuesto (haciendo la salvedad de que proceden de sentidos diferentes, pero al cabo ¿acaso aun siendo distintos la vista o el oído no usan la misma mecánica perceptiva?).

\footnotetext{
${ }^{50}$ Cfr. Ibid., p. 240 [p. 230].

${ }^{51}$ En resumen: "cuando el crítico carece de delicadeza, juzga sin distinguir y sólo le afectan las cualidades más gruesas y palpables del objeto. Los detalles más finos pasan inadvertidos y no son considerados. Cuando no cuenta con la ayuda de la práctica, su veredicto es confuso y vacilante. Cuando no se ha utilizado ninguna comparación, las bellezas más frívolas, que más bien merecen el nombre de defectos, son objeto de su admiración. Cuesto está bajo la influencia de prejuicios, todos sus sentimientos naturales están pervertidos. Cuando carece de buen sentido, no está cualificado para discernir las bellezas de un diseño o de un razonamiento, que son las más elevadas y excelentes" (Ibid. p. 241 [p. 231]).
}

Araucaria. Revista Iberoamericana de Filosofia, Política, Humanidades y Relaciones Internacionales, año $20, \mathrm{n}^{\circ} 40$ Segundo semestre de 2018. Pp. 311-332. ISSN 1575-6823 e-ISSN 2340-2199 doi: 10.12795/araucaria.2018.i40.14 
Merced a la simpatía es posible urbanizar el mundo de Mandeville pues con ella cabe pensar en un lugar donde la sensibilidad natural se puede afinar, donde se puede forzar la imaginación para crear nuevos modelos morales que la empatía nos llevará a sentir con viveza. Como se ve todo un esfuerzo social que hace pensar que el anatomista proporciona un campo mínimo pero vital al pintor, el del proceso de afinamiento social que no es muy diferente al afinamiento del gusto: ambos trabajan con sentimientos, aquello que hasta no hacía mucho se llamaban pasiones. 


\section{Referencias bibliográficas:}

T. Baceski, "Hume on Art Critics, Wise Men, and the Virtues of Taste", en Hume Studies, vol. 39, $\mathrm{n}^{\mathrm{o}}$ 2, 2013 (233-256).

S. Darwall, The British Moralists and the Internal 'Ought': 1640.1740, Cambridge, Cambridge University Press, 1995.

J. Harris, Hume: An Intellectual Biography, Cambridge, Cambridge University Press, 2015.

Albert O. Hirschmann, Las pasiones y los intereses: argumentos políticos en favor del capitalismo previos a su triunfo, Barcelona, Península, 1999.

Philip Mercer, Sympathy and Ethics, Oxford, Clarendon Press, 1972.

H. Monro, The Ambivalence of Bernard Mandeville, Oxford, Oxford University Press, 1975.

Hans D. Muller, "Sympathy for Whom? Smith's Reply to Hume" en Journal of the American Philosophical Association, 2016 (212-232).

Hans D. Muller, "Hume on Sympathy, Pity and Impartiality" incluido en G. Boros, J. Szalai \& O.I.Tóth (eds.), The Concepto of Affectivity in Early Modern Philosophy, Budapest, 2017, p. 259.

D. O'Brien, "Hume, Sympathy and Belief" incluido en G. Boros, J. Szalai \& O.I.Tóth (eds.), The Concept of Affectivity in Early Modern Philosophy, Budapest, 2017.

M. Peltonen, The Duel in Early Modern England, Cambridge University Press, 2003.

Gerald J. Postema, "'Cemented with Diseased Qualities': Sympathy and Comparison in Hume's Moral Psychology" en Hume Studies, Vol. 31, n ${ }^{\circ}$ 2, 2005 (249-298).

S.M. Purviance, "Intersubjetivity and Sociable Relations in the Philosophy of Francis Hutcheson" en EighteenthCentury Life, $\mathrm{n}^{\circ}$ 15, FebreroMayo de 1991 (2338).

A. Smith, An Inquiry into the Nature and Causes of the Wealth of Nations, Londres, Methuen, 1904 (reeditado por Liberty Fund).

T.A. Roberts, The Concept of Benevolence. Aspects of the EighteenthCentury Moral Philosophy, Londres, MacMillan Press, 1973.

Paul Russell, Freedom and Moral Sentiment. Hume's Way of Naturalizing Responsability, Oxford, Oxford University Press, 1995.

David Townsend, Hume's Aesthetic Theory: Taste and Sentiment, London, Routledge, 2005. 